even those supposed to be immune showed symptoms. It was noticed that nearly every case used milk from the company in question, and Dr. Parkes, our commissioner, at once prohibited more milk being brought from the locality previously referred to. I think no milk was brought here from that point after Thursday, January 17 , and immediately there was a falling off in new cases. W'ithin a week there were in Evanston city 137 cases, of which 99 per cent. showed connection with this particular milk supply. These cases were scattered, not being limited to any section of town (except as hereinafter stated), nor to any church, school or social set. The west side of town, inhabited chiefly by mechanics and laborers, gets its milk supply from local herds, and very little other milk was sold there. Consequently few cases occurred there.

The Chicago authorities did not prohibit the Wisconsin milk for more than a week after Dr. Parkes acted, and as a consequence when the epidemic was subsiding in Evanston it was increasing in Chicago, until in two days more cases were reported than ever before.

Finally, though the company in question has tried to make us believe that every precaution was taken to prevent infection we are convinced-to put it mildly-that they were mistaken. We have evidence that employes at the out-of-state plant and people on the farms from which the milk came were sick with scarlet fever.

When Dr. Parkes prohibited the receipt of milk from the suspected plant, the company attempted to ship butter and condensed milk in bottles from that station. The Department of Agriculture informs me that bulk condensed milk, while heated to a degree sufficient to kill tubercle bacilli, is not sufficiently heated, probably, to kill other pathogenic germs.

1243 Chicago Avenue.

Heniry B. Hemenway, M.D.

\section{Fig Packing in Smyrna.}

Fesirn, Egypt, Feb, 14, 1907.

To the Editor:-During a trip to Turkey last fall I learned some interesting and disagreeable facts concerning the fig packing industry, especially at Smyrna. Nothing about the factory was clean, neither the packers, the rooms nor the utensils. The season, of course, is short and the packing employes are enlisted from the street rabble and are said to include many women of questionable character. Those who have visited oriental cities know what the hygiene and physical conditions of the packers must be, coming from the most insanitary homes and belonging to a class where diseases of the most loathsome and infectious types run riot. The figs are packed by hand (the stems being bitten off with the packers' teeth) and are molded with their hands and mouths. During the process of packing the figs are dipped in sea water. This water is taken from the bay at the very shore and is decidedly filthy. Last year the Turkish government prohibited the use of water taken near the shore, but this, like all other orders of the Turk, was simply a device of the officials to extort money from the proprietors for the privilege of taking water from the most convenient place. Between the packers' mouths and hands and the polluted waters of Smyrna Bay one may judge what wonderful possibilities there are of contracting diseases from eating "choice Smyrna figs."

Our government has taken the right course regarding pure. food products in the United States. It certainly would be well to now turn its attention to those of foreign production and importation.

H. B. Hanson.

The Contro-Lateral Sign in Sciatica.--Moutard-Martin and Parturier reported at the last meeting of the Soc. Med. $d$ Hop. de Paris that in 5 cases of sciatica they noticed a hitherto undescribed sign of the affection. The patient reclines without a pillow, and the thigh on the sound side is raised and flexed on the pelvis as he lies still. At a certain point the flexion causes a sharp pain in the buttocks on the affected side. The pain is generally at the sciatic point, but not always, and it was noted with both neuralgia and neuritis of the sciatic nerve. They call it the "induced contro-lateral pain," and regard it as an important differentiating sign.

\section{Book Notices}

Allas and Text-Book of Human Anatomx. By J. Sobotta, Professor of Anatomy in the University of Wuirzburg. Edited with additions by J. P. McMurrich, A.M., Ph.D., Professor of Anatomy in the University of Michigan. Vols. I and II. Vol. I, Bones, Ligaments, Joints and Muscles. With 320 Illustrations, mostly in colors. Cloth. Pp. 258. Price, $\$ 6.00$ net. Vol. II, Viscera, including the IIeart. Cloth. Pp. 194. Price, $\$ 6.00$ net. Philadelphia: W. B.
Saunders Company, 1906.

In this book the text and atlas, which were published separately in the original German, are combined. Two volumes of convenient size have already appeared, covering bones, liga ments and muscles in the first, and viscera, including the heart, in the second. The vessels, nerves, etc., remain to be treated in forthcoming parts of the work.

The book is designed for students and practitioners rather than for specialists in anatomy, and is well adapted for its purpose. The illustrations are numerous and well selected. There are many lithographic plates which, in color and outline, reproduce more closely than those in most atlases tne actual appearance of dissecting room preparations. There are also a large number of extensive sections of the body in various planes. These are well illustrated and are valuable in showing the relations of viscera and other structures in their natural positions undisturbed by dissection. The representation of the individual bones of the skull each in a color of its own, in which it appears consistently throughout the series of pictures, is a good feature which should be of material help in the study of these structures. The text is simple, clear and concise and has been translated into good English by Dr. W. H. Thomas. A number of brief additions inserted in small type by the editor of the American edition add materially to its interest, and should stimulate the student to further anatomic study. Occasionally the results of recent anatomic investigation are introduced in this way, as for instance an account of the auriculo-ventricular muscle bundle of the heart, Vol. II, page 173.

The nomenclature is based on the B. N. A., the names adopted by the committee of the International Anatomical Association, which met in Basel in 1895. This nomenclature is much the best which has yet appeared. It was published en. tirely in Latin, and while something may be said in favor of translating the names into English in books for the use of English-speaking students, such changes are always at the expense of conformity with international usage. In this book some attempt has been made to adapt the Latin names to our vernacular. Many of them are translated into English, many are dropped, other names being substituted for them, while some are partly translated and left partly in their Latin forms. Some of these changes make the names more readily intelligible, but some are at the expense of accuracy, e. g., "greater tubercular ridge" for "crista tuberculi majoris," Figure 114. The ridge is not tubercular. "Obturator foramen" is used instead of "foramen obturatum," Vol. I, page 96. It is not logical to speak of a foramen as obturator, even though the term has been extensively used in English books. Changes are sometimes at the expense of clearness, for instance, the use of the name "ulnar lateral carpal ligament," instead of "ligamentum collaterale carpi ulnare," Figure 203.

The terms of direction and position are sometimes different from those of the B. N. A. Thus the latter uses "externus" always to indicate position near the body surface, and "lateralis" always to indieate position relatively distant from the median plane of the body. Lack of uniformity in the application and spelling of anatomic names is to be regretted, because the subject of anatomy is one especially adapted to develop in the student habits of accurate work and of accurate and definite statement of fact. While the changes made are of some advantage in that the names are more intelligible, the disadvantages seem more than sufficient to offset them, and on the whole the retention in texts and atlases of the international nomenclature unaltered would seem preferable. In this country we are in a transition stage in the matter of anatomic nomenclature, as is noted in the editor's preface, and we are still compelled to consider the older forms made familiar by 